\title{
Adverse effects of conjugated alpha-linolenic acids (CLnA) on lipoprotein profile on experimental atherosclerosis in hamsters
}

\author{
M. Plourde ${ }^{1,2 \dagger}$, M. Ledoux ${ }^{4}$, S. Grégoire ${ }^{1}$, L. Portois ${ }^{6}$, J. J. Fontaine ${ }^{5}$, Y. A. Carpentier ${ }^{6}$, \\ P. Angers ${ }^{2}$, J. M. Chardigny ${ }^{3}$ and J. L. Sébédio ${ }^{3}$ \\ ${ }^{1}$ INRA, UMR1234, F-21000 Dijon, France; ${ }^{2}$ INAF/STELA, Université Laval, Canada, G1K 7P4; ${ }^{3}$ INRA, UMR1019, Clermont-Ferrand, F-63000 France; CRNH \\ Auvergne, Clermont-Ferrand, F-63000, France; ${ }^{4}$ Unité Composition et Hygiène des Produits Laitiers, AFSSA, 23 Avenue du Général de Gaulle, F-94706 Maisons \\ Alfort Cedex, France; ${ }^{5}$ UP d'Histologie et Anatomie Pathologique, École Nationale Vétérinaire d'Alfort, F-94704 Maisons Alfort Cedex, France; ${ }^{6}$ Laboratory for \\ Experimental Surgery, ULB, Brussels, Belgium
}

(Received 26 September 2006; Accepted 6 March 2007)

\begin{abstract}
Conjugated linoleic acids (CLAs) such as rumenic acid (RA) have the potential to alter blood lipid profiles in animals and in humans. In contrast, physiological effects of conjugated $\alpha$-linolenic acids (CLnAs), which concomitantly are omega-3 and conjugated fatty acids, are still unknown. The aim of this study was to evaluate the potential of CLnA to interfere in early steps of atherosclerosis by altering lipoprotein profiles and fatty streaks in the aortas. $F_{1} B$ hamsters were fed a control or one of the three hypercholesterolemic (HC) diets: HC-control, HC-RA (18:2 cis-9, trans-11) or HC-CLnA (CLnA: equimolar mixture of 18:3 cis-9, trans-11, cis-15 and cis-9, trans-13, cis-15) diet. In low-cholesterol control-fed hamsters, the proportion of high-density lipoprotein cholesterol (HDL-C) was around $45 \%$ while in HC-fed hamsters, HDL-C was around 10\% and cholesterol was mostly (80\%) carried by triglyceride-rich lipoproteins (TRL). Low-density lipoprotein (LDL) triglycerides (TGs) increased by approximately $60 \%$ in hamsters fed either HC-RA or HC-CLnA compared with HC-controls but not compared with the low-cholesterol control diet. HDL cholesterol decreased by $24 \%$ and $16 \%$ in hamsters fed HC-RA and HC-CLnA, respectively. Small dense LDLcholesterol increased by approximately 60\% in hamsters fed HC-RA and HC-CLnA compared with the HC-control group and by more than a 100\% compared with hamsters on the control diet. The relative percentage of liver cholesteryl ester content increased by $88 \%$ in hamsters fed HC diets compared with the control diet. Significant differences in fatty streaks were observed between control and HC-diet-fed hamsters. However, no significant difference was observed among the HC-diet-fed hamsters. This study shows that animals fed any one of the HC diets developed an adverse lipoprotein profile compared with a normolipidic diet. Also, HC-RA or HC-CLnA diets altered lipoprotein profile compared with animals fed the HC-control diet but had no beneficial effects on atherosclerosis.
\end{abstract}

Keywords: conjugated alpha-linolenic acid, conjugated linoleic acid, fatty streaks, hamsters, lipoproteins

\section{Introduction}

The term conjugated linoleic acid (CLA) refers to a class of positional and geometric conjugated dienoic isomers of linoleic acid (18:2n-6) of which rumenic acid (RA, 18:2 cis-9, trans-11) and 18:2 trans-10, cis-12 are the main constituents. CLAs have unique biological properties (McLeod et al., 2004) among which an important but controversial observation is that CLA can alter lipoprotein metabolism and decrease the extent of atherosclerosis in experimental animals. For example, in rabbits, Lee et al. (1994) demonstrated that a mixture of CLA isomers reduces both

${ }^{\dagger}$ E-mail: m.plourde@usherbrooke.ca. Present address: Research Center on Aging, 1036 Belvédère sud, Sherbrooke, Québec, Canada J1H 4C4. low-density lipoprotein (LDL) cholesterol and arterial lipid accumulation. These effects were also later shown in rabbits fed a CLA mixture or single CLA isomers (such as RA or 18:2 trans-10, cis-12) provided in a semi-purified diet (Kritchevsky et al., 2004). Similar data were also reported using hamsters (Nicolosi et al., 1997; Gavino et al., 2000; Wilson et al., 2000 and 2006; Dorfman et al., 2003). CLA may also decrease the formation of fatty streaks in hamsters and rabbits (Lee et al., 1994; Kritchevsky et al., 2004) and may help to attenuate atherosclerosis by inducing apoptosis in the atherosclerotic lesion in mice (Toomey et al., 2006). However, a recent study on hamsters reported that there may be an isomer-dependent CLA effect in this rodent model (Macarulla et al., 2005). 
It is not completely clear whether RA or the $18: 2$ trans10 , cis-12 isomer is responsible for the biological effects of CLA. In humans, Tricon et al. (2004) reported that encapsulated RA (0.6-2.4 g/day) decreased the ratio of total cholesterol (TC):high-density lipoprotein (HDL) cholesterol while the 18:2 trans-10, cis-12 isomer had opposite effects. On the other hand, Desroches et al. (2005) detected no beneficial metabolic effects of a 10 -fold CLA mixture enrichment of butter fat in overweight and obese men.

Recently, conjugated $\alpha$-linolenic acids $(\mathrm{CLnA})$ have been identified in milk fat (Destaillats et al., 2005b). They occur between $0.05 \%$ and $0.3 \%$ of total fatty acids in both milk (Destaillats et al., 2005b) and bovine muscle (unpublished results). CLnA combines both omega-3 and conjugated double bonds. Among the isomers, 18:3 cis-9, trans-11, cis15 has the same conjugated double-bond system as RA. This CLnA isomer can be elongated and desaturated to a conjugated 22:6n-3 in rats following the same elongation/ desaturation pathway used by $\alpha$-linolenic acid (Destaillats et al., 2005a; Plourde et al., 2006). In parallel, CLA isomers can also be elongated and desaturated, then further metabolised to produce various CLA-derived eicosanoids and other novel mediators that may exhibit biological activities in their own right (Pariza et al., 2000). In fact, CLA and CLnA produce metabolites of different chain lengths, which may well be biologically active (Pariza et al., 2000; Plourde et al., 2006). Moreover, CLnA concomitantly are omega-3 and conjugated fatty acids, both properties being suggested to have benefits towards atherosclerosis.

Actually, the potential of CLnA to affect atherosclerosis is unknown, so the aim of this study was to determine whether CLnA could inhibit early stages of atherosclerosis involving plasma lipoproteins profiles or early fatty streaks formation. We compared CLnA to RA and a control group using $F_{1} B$ hamsters given a hypercholesterolemic $(H C)$ diet. This model was chosen since it is well known to develop fatty streaks in response to an HC diet (Dorfman et al., 2003) and was previously used to evaluate the impact of CLA (Nicolosi et al., 1997).

\section{Material and methods}

Fatty acids

RA (85\% pure, free fatty acid) was purchased from Natural Lipids (Hovdebygda, Norway) and was chosen for its structural resemblance to one CLnA isomer. CLnA (75\% pure, free fatty acid) was an equimolar mixture of two major isomers, 18:3 cis-9, trans-11, cis-15 and cis-9, trans-13, cis-15 kindly donated by Naturia Inc. (Sherbrooke, Canada).

High oleic sunflower and linseed oils were provided by Lesieur (Asnières, France) and Robbe SA (Compiègne, France), respectively. Lard was purchased in a local market in France. A mixture of high oleic sunflower oil and linseed oil $(98: 2 \mathrm{w} / \mathrm{w})$ was saponified with $1 \mathrm{~mol} / \mathrm{l} \mathrm{KOH}$ in ethanol $(95 \%)$ at $50^{\circ} \mathrm{C}$ for $2 \mathrm{~h}$ in a reflux system. The resulting free fatty acids comprised $1 \%(\mathrm{~g} / \mathrm{kg})$ of the hypercholesterolemic control diet (HC-control).

\section{Animals and diets}

Male Golden Syrian $\mathrm{F}_{1} \mathrm{~B}$ hybrid hamsters $(n=45 ; 8$ weeks old; $103.3 \pm 8.0 \mathrm{~g}$; Biobreeders Inc., Fitchburg, MA, USA) were housed in groups of two and maintained in a controlled environment $\left(22 \pm 1{ }^{\circ} \mathrm{C} ; 55-60 \%\right.$ relative humidity) with a 12-h light:dark cycle according to French regulations (Authorization \#A21200 for the environment and 21CAE056 to JMC). They were acclimatised for 4 days with a semiliquid diet composed of a powdered commercial chow-base in which $6 \%$ of a mixture of high oleic sunflower oil:linseed oil $(98: 2 \mathrm{w} / \mathrm{w})$ was added. Following the acclimatisation time, the hamsters were randomly assigned to one of the four dietary groups. Three hamsters were fed a control normolipic diet (commercial rat/mice/hamster chow-base Augy, France) (Reeves et al., 1993) in order to assess the efficiency of the $\mathrm{HC}$ diets. The remaining 42 hamsters were allocated to one of the three HC diets ( $n=14$ per group). The HC diets contain $(\mathrm{g} / \mathrm{kg})$ wheat starch 282.3 , lipids 230 , cholesterol 1.2, sucrose 205.3, casein 196.8, mineral mixture 42.8 , cellulose 30.0 and vitamins mix 12.8 . The $230 \mathrm{~g} / \mathrm{kg}$ of lipids was divided as following: lard 200, sunflower oil 20 and high oleic sunflower oil:linseed oil 98:2 v/v, RA or ClnAfree fatty acids 10 . The control and the $\mathrm{HC}$ diets were given as a semi-liquid mixture for 12 weeks. The fatty-acid composition of the four diets is given in Table 1.

The animals were weighed twice a week. At the end of the experimental period, the hamsters were fasted for $16 \mathrm{~h}$, weighed, anaesthetised using isofurane and ex-sanguinated by abdominal aortic blood puncture. Plasma was obtained after blood centrifugation $(700 \times \mathbf{g})$ at $4^{\circ} \mathrm{C}$ for $10 \mathrm{~min}$ and stored at $-80^{\circ} \mathrm{C}$ until ultracentrifugation. The aortas were excised for analysis of fatty streaks (see later for more

Table 1 Fatty acid profile (\%) of the control and the three hypercholesterolemic diets containing $23 \%$ (in weight) of lipids and $0.12 \%$ of cholesterol

\begin{tabular}{|c|c|c|c|c|}
\hline & \multicolumn{4}{|c|}{$\operatorname{Diet}^{\dagger}$} \\
\hline & Control $^{\ddagger}$ & HC-control ${ }^{\S}$ & HC-RA ${ }^{\S}$ & $\mathrm{HC}-\mathrm{Cln} \mathrm{A}^{\S}$ \\
\hline 14:0 & - & 1.3 & 1.3 & 1.4 \\
\hline $16: 0$ & 14.9 & 23.0 & 23.0 & 23.4 \\
\hline $16: 1 n-9$ & - & 0.3 & 0.3 & 0.3 \\
\hline $16: 1 n-7$ & 1.1 & 2.3 & 2.3 & 2.3 \\
\hline $18: 0$ & 6.0 & 12.5 & 12.5 & 12.3 \\
\hline $18: 1 n-9$ & 33.1 & 39.8 & 36.6 & 36.5 \\
\hline 18:1n-7 & - & 2.8 & 2.8 & 2.8 \\
\hline $18: 2 n-6$ & 43.8 & 15.8 & 15.4 & 15.9 \\
\hline $18: 3 n-3$ & & 0.9 & 0.7 & 0.9 \\
\hline $20: 0$ & - & 0.2 & 0.2 & 0.2 \\
\hline $18: 2 \mathrm{c} 9, \mathrm{t} 11$ & - & - & 3.5 & 0.1 \\
\hline $18: 2 \mathrm{t} 10, \mathrm{c} 12$ & - & - & 0.4 & 0.1 \\
\hline $\begin{array}{l}18: 3 c 9, \mathrm{t} 11, \mathrm{c} 15+\mathrm{c} 9, \\
\mathrm{t} 13, \mathrm{c} 15\end{array}$ & - & - & - & 2.7 \\
\hline
\end{tabular}

${ }^{\dagger}$ Abbreviations are: $\mathrm{HC}$-control $=$ hypercholesterolemic control diet, HC-RA = hypercholesterolemic rumenic acid diet, HC-ClnA = hypercholesterolemic conjugated alpha-linolenic acids diet.

${ }^{\ddagger}$ Fatty acid profile provided by the supplier.

${ }^{\S}$ Fatty acid profile done on two samples. 
details) and livers were stored in chloroform:methanol $(2: 1 \mathrm{v} / \mathrm{v})$ at $-20^{\circ} \mathrm{C}$ for lipid extraction.

\section{Lipoproteins analysis}

Triglycerides (TG) and TC were measured in plasma and lipoprotein using enzymatic kits, triacylglycerol GPOPAP and cholesterol PAP (Roche Diagnostics, Vilvoorde, Belgium), respectively. Plasma lipoproteins were isolated by sequential ultracentrifugation at $4^{\circ} \mathrm{C}$ using a Beckman $\mathrm{TL}$ 100 centrifuge (Beckman Instrument Inc., Fullerton, $C A$, USA) with a fixed-angle rotor (TLA 100.2, Beckman Instrument Inc.) (Havel et al., 1955). The lipoproteins with a density lower than $1.063 \mathrm{~g} / \mathrm{ml}$ were classified as LDL while the ones equal or above that density were classified as HDL. The LDL fraction was further separated at density ranges between 1.019 and $1.063 \mathrm{~g} / \mathrm{ml}$ (Chapman et al., 1988). LDL profiles were then determined by isopycnic ultracentrifugation. Briefly, the LDL fraction was adjusted to density $=1.040 \mathrm{~g} / \mathrm{ml}$ and layered between potassium bromide solutions (containing EDTA and sodium azide $0.01 \%$ ) of different densities $(1.019,1.025,1.040,1.054$ and $1.085 \mathrm{~g} / \mathrm{ml}$ ) and centrifuged for $40 \mathrm{~h}\left(40000\right.$ r.p.m.; $\left.4^{\circ} \mathrm{C}\right)$ in a Beckman XL 100K ultracentrifuge equipped with a swinging bucket rotor (SW41Ti, Beckman Instrument Inc.). A highdensity potassium bromide solution $(1.29 \mathrm{~g} / \mathrm{ml})$ was then injected from the bottom of the tube (2232 Microperpex $S$ Peristaltic Pump, LKB, Bromma, Sweden) to collect 25 subfractions (each of $450 \mu \mathrm{l}$ ) of increasing densities. Density and cholesterol content were measured in each subfraction as described above.

\section{Liver lipid analysis}

Liver total lipids were extracted using a mixture of chloroform/methanol 2:1 v/v (Folch et al., 1957). Quantitative analysis of lipid classes were done using thin-layer chromatography coupled with flame ionisation detector (Sebedio and Juaneda, 1991). The elution solvent used for the migration of the samples applied on the rods was composed of hexane/diethyl ether/glacial acetic acid (80:20:1 v/v/v).

\section{Fatty streak analysis of the aorta}

After ex-sanguination, the heart cavities and arteries were washed through the left ventricle using formalin 10\% (v/v) at $\mathrm{pH} 7$ under physiological pressure. The whole thoracic cage was then fixed for $24 \mathrm{~h}$ in formalin $10 \%$. Following this period, the fixed aorta was dissected and stored in a phosphate-buffered saline solution at $4^{\circ} \mathrm{C}$ before staining. The whole aortic arch and descending aorta were then opened longitudinally from the anterior side. The tissues were washed with $70 \%$ isopropanol, stained for $15 \mathrm{~min}$ in Oil Red $0(0.5 \%$ in $70 \%$ isopropanol) and then washed again for $30 \mathrm{~s}$ with isopropanol and distilled water. The aortas were then immersed a few seconds in a $1 \%$ toluidine blue solution before being rinsed with distilled water and opened on the posterior arch. The two half aortas were fixed on a slide and were examined with a light microscope
(Leica DMR equipped with a Sony camera) under different magnifications. The picture acquisition used a Meteor II card and the Tribvn ICS 1.3.0.10 software. Four evaluators (unaware of the diet allocation) classified the aortic histological pictures into five groups in accordance with the extent of fatty streaks. Each aorta received a score between 0 and 4; aortas without any streak obtained 0 score, while maximal streaks scored 4 . The qualitative representation of the data using symbols $(+)$ was determined with the average score determined above. The scores above 2.5 received the mention +++ .

\section{Statistical analysis}

Plasma and lipoprotein TG and TC as well as liver lipid class data were compared by a one-way ANOVA with NCSS 6.01 Software (Alsyd, Meylan, France). Post hoc analyses were done using the Newman-Keuls test. Values with a $P \leqslant 0.05$ were significant. Fatty streak scores were compared using the non-parametric Kruskal-Wallis test.

\section{Results}

\section{Animals}

At the end of the experimental period, no difference in food intake or final BW was observed between hamsters fed the control or any of the three HC diets (Table 2). All the hamsters fed any one of the $\mathrm{HC}$ diets had liver steatosis as determined by their increased weight, increased total lipid per gram of liver and by their colour and shape (light pink instead of dark red and covered with red dots), compared with the hamster fed the control diet (data not shown).

\section{Plasma lipids and lipoproteins}

TC and TG in hamsters fed the control diet was significantly lower than in hamsters fed any one of the three HC diets (Table 3). The results obtained for TC and TG on plasma were higher than expected and, any of the three $\mathrm{HC}$ diets induce an atherogenic lipoprotein profile as seen by the high values for TC and total TG compared with control. HDL-C decreased by $24 \%$ and $16 \%$ in hamsters fed HC-RA and $\mathrm{HC}-\mathrm{C} \ln \mathrm{A}$, respectively, compared with the $\mathrm{HC}$-control diet. Plasma TG content was significantly higher (38\%) in

Table 2 Mean \pm s.e. for body weight (BW) $(g)$ and food consumption (g/day) during the experimental period in hamsters fed a control or a hypercholesterolemic control, RA or CLnA diet

\begin{tabular}{lcccc}
\hline \hline & \multicolumn{4}{c}{ Diet $^{\dagger}$} \\
& $\begin{array}{l}\text { Control } \\
n=3\end{array}$ & $\begin{array}{c}\text { HC-control } \\
n=14\end{array}$ & $\begin{array}{c}\text { HC-RA } \\
n=14\end{array}$ & $\begin{array}{c}\text { HC-CLnA } \\
n=14\end{array}$ \\
& & & & \\
\hline Initial BW & $104.3 \pm 4.0$ & $103.6 \pm 8.6$ & $103.1 \pm 7.8$ & $103.5 \pm 8.3$ \\
Final BW & $177.3 \pm 8.3$ & $168.4 \pm 17.3$ & $181.5 \pm 12.7$ & $176.3 \pm 14.4$ \\
Food & N/D & $10.0 \pm 0.5$ & $10.8 \pm 0.3$ & $10.9 \pm 0.8$ \\
consumption & & & & \\
\hline \hline
\end{tabular}

\footnotetext{
${ }^{+}$Abbreviations are: HC-control = hypercholesterolemic control diet, HC-RA = hypercholesterolemic rumenic acid diet, HC-ClnA = hypercholesterolemic conjugated alpha-linolenic acids diet.
} 
Plourde, Ledoux, Grégoire, Portois, Fontaine, Carpentier, Angers, Chardigny and Sébédio

Table 3 Means \pm s.e. for plasma triglyceride (TG) and cholesterol ( $\mathrm{mg} / \mathrm{dl})$ concentrations of hamsters fed a control or a hypercholesterolemic control, RA or CLnA diet

\begin{tabular}{|c|c|c|c|c|}
\hline & \multicolumn{4}{|c|}{$\operatorname{Diet}^{\dagger}$} \\
\hline & $\begin{array}{c}\text { Control } \\
n=3\end{array}$ & $\begin{array}{c}\text { HC-control } \\
n=12\end{array}$ & $\begin{array}{l}\text { HC-RA } \\
n=14\end{array}$ & $\begin{array}{c}\mathrm{HC}-\mathrm{CLnA} \\
n=14\end{array}$ \\
\hline \multicolumn{5}{|c|}{ Plasma parameters ${ }^{\ddagger}$} \\
\hline \multicolumn{5}{|c|}{ Cholesterol (mg/dl) } \\
\hline Total & $110^{a} \pm 15$ & $654^{b} \pm 157$ & $785^{b} \pm 93$ & $798^{b} \pm 91$ \\
\hline TRL & $25^{a} \pm 10$ & $523^{b} \pm 208$ & $686^{b} \pm 130$ & $656^{b} \pm 79$ \\
\hline LDL & $19.8^{\mathrm{a}} \pm 3.2$ & $69.6^{\mathrm{b}} \pm 9.6$ & $62.9^{b} \pm 10.3$ & $70.2^{b} \pm 9.6$ \\
\hline $\mathrm{HDL}$ & $49.5^{a} \pm 6.7$ & $96.3^{b} \pm 12.2$ & $73.3^{c} \pm 8.0$ & $81.2^{C} \pm 12.6$ \\
\hline \multicolumn{5}{|c|}{$\mathrm{TG}(\mathrm{mg} / \mathrm{dl})$} \\
\hline Total & $225^{c} \pm 81$ & $1508^{a} \pm 451$ & $1873^{\mathrm{ab}} \pm 448$ & $2090^{b} \pm 236$ \\
\hline TRL & $138^{a} \pm 67$ & $1424^{b} \pm 459$ & $1737^{b} \pm 488$ & $1865^{b} \pm 311$ \\
\hline LDL & $19.4^{\mathrm{ab}} \pm 1.2$ & $12.31^{\mathrm{a}} \pm 7.8$ & $22.8^{\mathrm{ab}} \pm 11.5$ & $19.1^{\mathrm{ab}} \pm 4.9$ \\
\hline HDL & $16.4 \pm 1.6$ & $21.5 \pm 7.7$ & $19.7 \pm 4.0$ & $21.4 \pm 6.9$ \\
\hline
\end{tabular}

a,b,c Values not sharing the same letters are significantly different $(P<0.05)$.

${ }^{\dagger}$ Abbreviations are: HC-control = hypercholesterolemic control diet, HC-RA = hypercholesterolemic rumenic acid diet, HC$\mathrm{ClnA}=$ hypercholesterolemic conjugated alpha-linolenic acids diet.

${ }^{\ddagger} \mathrm{TRL}=$ triglyceride-rich lipoprotein, $\mathrm{LDL}=$ low-density lipoprotein, $\mathrm{HDL}=$ high-density lipoprotein.

Table 4 Means \pm s.e. for total cholesterol content ( $\mu$ mol/l) of lowdensity lipoproteins (LDL) separated by discontinuous density gradient in hamsters fed a control or a hypercholesterolemic control, RA or CLnA diet

\begin{tabular}{ccccc}
\hline \hline & \multicolumn{4}{c}{ Diet $^{\dagger}$} \\
\cline { 2 - 5 } & $\begin{array}{c}\text { Control } \\
n=3\end{array}$ & $\begin{array}{c}\text { HC-control } \\
n=12\end{array}$ & HC-RA & HC-CLnA \\
& & & $n=14$ & $n=14$ \\
\hline Density (g/ml) & & & & \\
$<1.040$ & $357^{\mathrm{b}} \pm 39$ & $1067^{\mathrm{a}} \pm 51$ & $1113^{\mathrm{a}} \pm 96$ & $926^{\mathrm{a}} \pm 63$ \\
$\geqslant 1.040^{\ddagger}$ & $253^{\mathrm{a}} \pm 10$ & $341^{\mathrm{a}} \pm 39$ & $537^{\mathrm{b}} \pm 25$ & $545^{\mathrm{b}} \pm 38$ \\
\hline
\end{tabular}

a,b Values in rows having similar superscripts are not statistically different $(P>0.05)$.

${ }^{+}$Abbreviations are: $\mathrm{HC}$-control $=$ hypercholesterolemic control diet, $\mathrm{HC}-\mathrm{RA}=$ hypercholesterolemic rumenic acid diet, HC-ClnA = hypercholesterolemic conjugated alpha-linolenic acids diet.

${ }^{\ddagger}$ sdLDL = small dense low-density lipoproteins.

animals fed HC-CLnA compared with the HC-control diet. Plasma LDL-TG increased by $70 \%$ in hamsters fed the HCRA or HC-CLnA diets compared with the HC-control but were similar to control-fed hamsters.

TC content in the small dense low-density lipoprotein (sdLDL, $d \geqslant 1.040 \mathrm{~g} / \mathrm{ml}$ ) fraction was approximately $60 \%$ higher in animals fed HC-RA and HC-CLnA diets compared with HC-control animals and more than a 100\% compared with the control diet (Table 4; Figure 1). The sdLDL profile in hamsters fed the control diet was lower than the $\mathrm{HC}$ groups because of the lower LDL TC content.

\section{Liver lipids}

The relative \% of cholesterol esters (CE) in liver of animals fed the HC diets increased by $88 \%$ compared with the control diet (Figure 2). This lower relative \% of CE in livers of hamsters fed the control diet was balanced by a $58 \%$ and $66 \%$ increase in phospholipid (PL) and TG, respectively

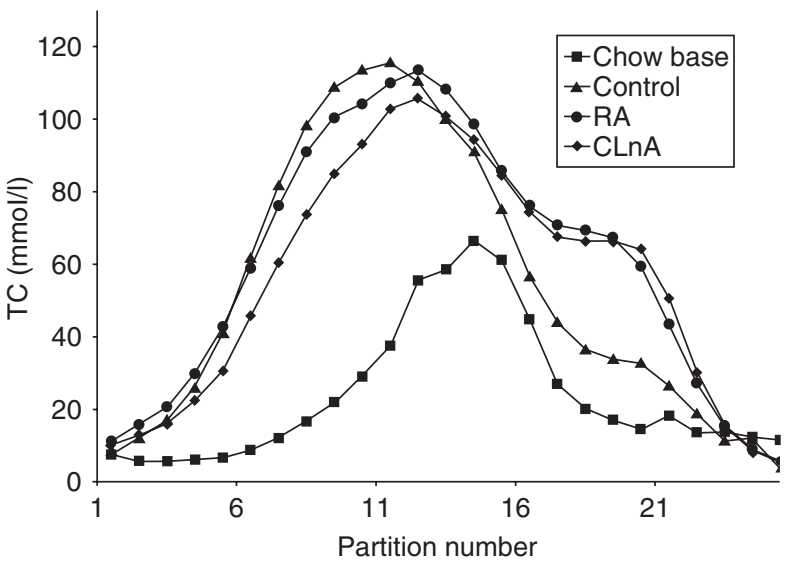

Figure 1 Density profiles of low-density lipoproteins of hamsters fed a control or a hypercholesterolemic control, RA or CLnA diet. The partition number 15 corresponds to a density of $1.040 \mathrm{~g} / \mathrm{ml}$. HC-control = hypercholesterolemic control diet, HC-RA = hypercholesterolemic rumenic acid diet, $\mathrm{HC}-\mathrm{CLnA}=$ hypercholesterolemic conjugated alpha-linolenic acids diet, $\mathrm{TC}=$ plasma total cholesterol.

when compared with the $\mathrm{HC}$ diets. Among the three $\mathrm{HC}$ diets, no significant difference was observed in the liver $C E$, TG, free cholesterol or PL content.

\section{Fatty streaks}

The aortas fatty streaks score was $94 \%$ higher in hamsters fed the HC diets compared with the control diet. No significant difference was observed among the three $\mathrm{HC}$ groups, even though the scores tended to be slightly lower in the RA group (Table 5).

\section{Discussion}

In the present study, we did not observe any beneficial effect of an HC diet containing RA and CLnA on plasma lipids and aorta fatty streaks compared with an HC control 


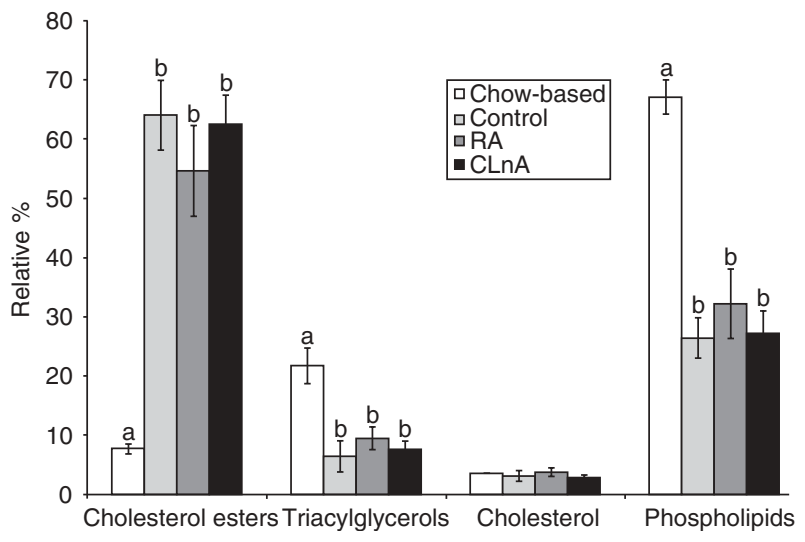

Figure 2 Liver lipid class profile (\%) of hamsters fed a control or a hypercholesterolemic control, RA or CLnA diet. Results are expressed as mean of 14 independent values \pm s.e. $\mathrm{HC}$-control = hypercholesterolemic control diet, HC-RA = hypercholesterolemic rumenic acid diet, HC$\mathrm{CLnA}=$ hypercholesterolemic conjugated alpha-linolenic acids diet, $\mathrm{CE}=$ cholesterol esters, $\mathrm{TG}=$ triglycerides, $\mathrm{PL}=$ phospholipids.

Table 5 Hamster aorta fatty streaks scores following a control or a hypercholesterolemic control, RA or CLnA diet

\begin{tabular}{llccc}
\hline \hline & \multicolumn{4}{c}{ Diet $^{\dagger}$} \\
\cline { 2 - 5 } & $\begin{array}{c}\text { Control } \\
n=3\end{array}$ & $\begin{array}{c}\text { HC-Control } \\
n=14\end{array}$ & $\begin{array}{c}\text { HC-RA } \\
n=14\end{array}$ & $\begin{array}{c}\text { HC-CLnA } \\
n=14\end{array}$ \\
\hline Mean score values & $0.17^{\mathrm{a}}$ & $\begin{array}{c}2.65^{\mathrm{b}} \\
+++\end{array}$ & $\begin{array}{c}2.42^{\mathrm{b}} \\
++\end{array}$ & $\begin{array}{c}2.60^{\mathrm{b}} \\
+++\end{array}$ \\
\hline \hline
\end{tabular}

${ }^{+}$Abbreviations are: $\mathrm{HC}$-control $=$ hypercholesterolemic control diet, $\mathrm{HC}-\mathrm{RA}=$ hypercholesterolemic rumenic acid diet, HC-ClnA = hypercholesterolemic conjugated alpha-linolenic acids diets.

group. However, we showed that plasma TG and TC of the hamsters fed any one of the HC diets was increased compared with the hamsters fed the control diet. TC of hamsters fed the $\mathrm{HC}$ diets was mainly carried by plasma triglyceride-rich lipoprotein (TRL) instead of HDL as in the control-fed animals. Also, the HC diets increased several risk factors, and these animals had fatty streaks in the aortas. Their liver lipid content was also associated with a higher level of CE compared with the control diet. This suggests a modification in cholesterol metabolism leading to early steps of atherosclerosis when hamsters were fed an HC diet.

In our experimental conditions, HC-CLnA decreased the $\mathrm{HDL}-\mathrm{C}$ in plasma similar to HC-RA. There was no beneficial effect on lipoprotein profile and fatty streaks in the aortas of animals fed the HC-CLnA diet. However, this result did not exclude the beneficial effects of CLnA on early steps of atherosclerosis in animals, considering that the effect of a single CLnA isomer has not yet been investigated. In fact, the overall activity of a CLnA mixture may be directed by one of the two isomers as demonstrated in a previous study (Plourde et al., 2006). Only the $c-9, t-11, c-1518: 3$ isomer is metabolised to conjugated $20: 5 n-3$ and $22: 6 n-3$ isomers and this may have a greater role in biochemical and signalisation pathways as was hypothesised for other conjugated fatty acids (Valeille et al., 2004). It has already been shown that CLA isomers can also be elongated and desaturated, then further metabolised to produce various CLAderived eicosanoids and other novel mediators that may exhibit biological activities in their own right (Pariza et al., 2000). However, even if both isomers are metabolised, it is not completely clear right now which one is the more potent to affect atherosclerosis and modulate lipoproteins in animals and humans. Thus, the utilisation of a CLnA mixture in this study may have had an impact on the overall activity of the isomers and the results would have probably been different if we had to use single pure isomers.

In this study, we decided to use only RA as one CLA isomer because of its structural similarities with one C LnA isomer (18:3 cis-9, trans-11, cis-15). Moreover, RA may be more active in preventing atherosclerosis in animals (Valeille et al., 2004; Lock et al., 2005). A diet containing 18:2 trans10 , cis-12 appears to have a profound proatherogenic effect, while RA impeded the development of atherosclerosis in mice (Arbones-Mainar et al., 2006), an effect possibly explained by increased epithelial permeability with trans -10 , cis-12 but not with RA (Roche et al., 2001).

Although the beneficial effects of CLA and possibly CLnA in hamsters seem to be isomer-dependent, other experimental conditions and design could also have had a major influence on the results (Yoganathan et al., 1998; Dorfman et al., 2003; Macarulla et al., 2005; Wilson et al., 2006). For example, gene expression for receptors is sensitive to the hamster strain and to the lipid composing the diet (Loison et al., 2002). The hamster strain used in this study is recognised as forming fatty streaks and to be more sensitive to HC diets (Dorfman et al., 2003). It is also a good model because of its association with a higher activity of cholesterol ester transfer protein than other rodents (Tsutsumi et al., 2001). However, in this study, the hamsters showed higher TC concentrations than elsewhere although it was the same hamster strain and approximately the same experimental design (Wilson et al., 2000). This may relate in part to the housing conditions (two by two) used in this experiment, which seems to have affected plasma lipid concentrations and early atherogenesis as previously reported by Yoganathan et al. (1998). However, it can also be related to the amount of other fats in the diet, which could largely modify the lipoprotein profile when supplemented with CLA (Valeille et al., 2004). In this context, the introduction of $20 \%$ lard in our HC diet instead of $20 \%$ coconut oil may have created an important fatty-acid modification interfering with CLA properties. The high fat content of the $\mathrm{HC}$ diets may also have induced an early propensity to atherosclerosis as seen by the high CE in liver and the fatty streaks. This result has not been noticed in other studies such as that of Valeille et al. (2004) showing beneficial effects of RA on atherosclerosis. This may explain in part the different potential of RA to influence proatherogenic TC concentrations and aortic fatty streaks formation. The high TC found in hamsters fed the HC-RA or HC-CLnA resulted in higher proportion of SdLDL, which are possibly associated with the increase in fatty streaks 
Plourde, Ledoux, Grégoire, Portois, Fontaine, Carpentier, Angers, Chardigny and Sébédio

formation. It has already been reported that sdLDL are more sensitive to oxidation and transformation into endothelial wall (Hamilton, 1997) and may increase fatty streak formation. This study shows that $\mathrm{HC}$ hamsters had more sdLDL and fatty streaks than control-fed hamsters but no difference was observed among the HC-diet-fed hamsters.

In conclusion, using hamsters, we did not find that feeding an $\mathrm{HC}$ diet enriched in either RA or CLnA lowers proatherogenic TC concentrations compared with $\mathrm{HC}$ controls. These results suggest that RA or CLnA do not beneficially modify the lipoprotein profile or fatty streak formation in $F_{1} B$ hamsters fed an $\mathrm{HC}$ diet. Our results differ from other data on hamsters supplemented with RA (Nicolosi et al., 1997; Valeille et al., 2004). In this study, the pronounced atherogenic status of hamsters fed one of the HC diet compared with the animals fed the control diet may explain in part the discrepancy of our results compared with other literature. Regarding CLnA, further work will be needed to see how single CLnA isomers could influence atherosclerosis and lipoprotein profile in other experimental conditions.

\section{Acknowledgements}

The authors are grateful to Fonds Québécois de Recherche sur la Nature et les Technologies (FQRNT) and Naturia Inc. (Sherbrooke, Canada) for a Ph.D. scholarship to M. Plourde.

\section{References}

Arbones-Mainar JM, Navarro MA, Guzman MA, Arnal C, Surra JC, Acin S, Carnicer R, Osada J and Roche HM 2006. Selective effect of conjugated linoleic acid isomers on atherosclerotic lesion development in apolipoprotein $E$ knockout mice. Atherosclerosis 189, 318-327.

Chapman MJ, Laplaud PM, Luc G, Forgez P, Bruckert E, Goulinet S and Lagrange D 1988. Further resolution of the low density lipoprotein spectrum in normal human plasma: physicochemical characteristics of discrete subspecies separated by density gradient ultracentrifugation. Journal of Lipid Research 29, 442-458.

Desroches S, Chouinard PY, Galibois I, Corneau L, Delisle J, Lamarche B, Couture P and Bergeron N 2005. Lack of effect of dietary conjugated linoleic acids naturally incorporated into butter on the lipid profile and body composition of overweight and obese men. American Journal of Clinical Nutrition 82, 309-319.

Destaillats F, Berdeaux 0, Sebedio JL, Juaneda P, Gregoire S, Chardigny JM, Bretillon L and Angers P 2005a. Metabolites of conjugated isomers of alphalinolenic acid $(C \operatorname{Ln} A)$ in the rat. Journal of Agriculture and Food Chemistry 53, 1422-1427.

Destaillats F, Trottier JP, Galvez JMG and Angers P 2005b. Analysis of alphalinolenic acid biohydrogenation intermediates in milk fat with emphasis on conjugated linolenic acids. Journal of Dairy Science 88, 3231-3239.

Dorfman SE, Smith DE, Osgood DP and Lichtenstein AH 2003. Study of dietinduced changes in lipoprotein metabolism in two strains of Golden-Syrian hamsters. Journal of Nutrition 133, 4183-4188.

Folch J, Lees M and Sloanestanley GH 1957. A simple method for the isolation and purification of total lipids from animal tissues. Journal of Biological Chemistry 226, 497-509.

Gavino VC, Gavino G, Leblanc MJ and Tuchweber B 2000. An isomeric mixture of conjugated linoleic acids but not pure cis-9 trans-11-octadecadienoic acid affects body weight gain and plasma lipids in hamsters. Journal of Nutrition 130, 27-29.

Hamilton CA 1997. Low-density lipoprotein and oxidised low-density lipoprotein: their role in the development of atherosclerosis. Pharmacology and Therapeutics $74,55-72$.
Havel J, Eder HA and Bragdon H 1955. The distribution and chemical composition of ultracentrifugally separated lipoproteins in human serum. Journal of Clinical Investigation 34, 1345-1353.

Kritchevsky D, Tepper SA, Wright S, Czarnecki SK, Wilson TA and Nicolosi RJ 2004. Conjugated linoleic acid isomer effects in atherosclerosis: growth and regression of lesions. Lipids 39, 611-616.

Lee KN, Kritchevsky D and Pariza MW 1994. Conjugated linoleic acid and atherosclerosis in rabbits. Atherosclerosis 108, 19-25.

Lock AL, Horne CA, Bauman DE and Salter AM 2005. Butter naturally enriched in conjugated linoleic acid and vaccenic acid alters tissue fatty acids and improves the plasma lipoprotein profile in cholesterol-fed hamsters. Journal of Nutrition 135, 1934-1939.

Loison C, Mendy F, Serougne C and Lutton C 2002. Dietary myristic acid modifies the $\mathrm{HDL}$-cholesterol concentration and liver scavenger receptor $\mathrm{BI}$ expression in the hamster. British Journal of Nutrition 87, 199-210.

Macarulla MT, Fernandez-Quintela A, Zabala A, Navarro V, Echevarria E, Churruca I, Rodriguez VM and Portillo MP 2005. Effects of conjugated linoleic acid on liver composition and fatty acid oxidation are isomer-dependent in hamster. Nutrition 21, 512-519.

McLeod RS, LeBlanc AM, Langille MA, Mitchell PL and Currie DL 2004. Conjugated linoleic acids atherosclerosis, and hepatic very-low-density lipoprotein metabolism. American Journal of Clinical Nutrition 79 1169S-1174S.

Nicolosi RJ, Rogers EJ, Kritchevsky D, Scimeca JA and Huth PJ 1997. Dietary conjugated linoleic acid reduces plasma lipoproteins and early aortic atherosclerosis in hypercholesterolemic hamsters. Artery 22, 266-277.

Pariza MW, Park Y and Cook ME 2000. Mechanisms of action of conjugated linoleic acid: evidence and speculation. Proceedings of the Society for Experimental Biology and Medicine 223, 8-13.

Plourde M, Sergiel JP, Chardigny JM, Gregoire S, Angers P and Sebedio JL 2006. Absorption and metabolism of conjugated alpha-linolenic acids given as free fatty acids or triacylglycerols in rats. Nutrition and Metabolism 3, 8.

Reeves PG, Nielsen FH and Fahey GC 1993. AIN-93 purified diets for laboratory rodents: final report of the American Institute of Nutrition ad hoc writing committee on the reformulation of the AIN-76A rodent diet. Journal of Nutrition 123, 1939-1951.

Roche HM, Terres AM, Black IB, Gibney MJ and Kelleher D 2001. Fatty acids and epithelial permeability: effect of conjugated linoleic acid in Caco-2 cells. Gut 48, 797-802.

Sebedio JL and Juaneda P 1991. Quantitative lipid analyses using the new latroscan TLC-FID system. Journal of Planar Chromatography - Modern TLC 4, 35-41.

Toomey S, Harhen B, Roche HM, Fitzgerald D and Belton 0 2006. Profound resolution of early atherosclerosis with conjugated linoleic acid. Atherosclerosis 187, 40-49.

Tricon S, Burdge GC, Kew S, Banerjee T, Russell JJ, Jones EL, Grimble RF, Williams CM, Yaqoob P and Calder PC 2004. Opposing effects of cis-9 trans-11 and trans-10, cis-12 conjugated linoleic acid on blood lipids in healthy humans. American Journal of Clinical Nutrition 80, 614-620.

Tsutsumi K, Hagi A and Inoue $Y$ 2001. The relationship between plasma high density lipoprotein cholesterol levels and cholesteryl ester transfer protein activity in six species of healthy experimental animals. Biological and pharmaceutical bulletin 24, 579-581.

Valeille K, Gripois D, Blouquit MF, Souidi M, Riottot M, Bouthegourd JC, Serougne $C$ and Martin JC 2004. Lipid atherogenic risk markers can be more favourably influenced by the cis-9 trans-11-octadecadienoate isomer than a conjugated linoleic acid mixture or fish oil in hamsters. British Journal of Nutrition 91, 191-199.

Wilson TA, Nicolosi RJ, Chrysam M and Kritchevsky D 2000. Conjugated greater than linoleic acid in hypercholesterolemic hamsters. Nutrition Research 20, 1795-1805.

Wilson TA, Nicolosi RJ, Saati A, Kotyla T and Kritchevsky D 2006. Conjugated linoleic acid isomers reduce blood cholesterol levels but not aortic cholesterol accumulation in hypercholesterolemic hamsters. Lipids 41 , 41-48

Yoganathan S, Wilson TA and Nicolosi RJ 1998. Housing conditions effect plasma lipid concentrations and early atherogenesis independent of treatment in hamsters. Nutrition Research 18, 83-92. 